\title{
Parameters Affecting Efficiency of Centrifugal Pump A Review
}

\author{
Shivani Kaustubh Chitale ${ }^{1}$, Pranjal Nitin Jadhav², Snehal Suresh Dhoble², Dr. Mr. Satyajeet Deshmukh ${ }^{3}$ \\ ${ }^{*}$ Student, Chemical Engineering Department, Datta Meghe College of Engineering, Navi Mumbai, \\ Maharashtra, India \\ 2Final year student, Chemical Engineering Department, Datta Meghe College of Engineering, Navi Mumbai, \\ Maharashtra, India \\ ${ }^{3}$ Mentor, Chemical Engineering Department, Datta Meghe College of Engineering, Navi Mumbai, Maharashtra, \\ India
}

\begin{abstract}
Article Info

Volume 8, Issue 6

Page Number : 49-58

\section{Publication Issue}

November-December-2021

\section{Article History}

Accepted : 01 Nov 2021

Published : 08 Nov 2021

The pump is used as one of the most significant components in chemical industry so without its existence process may not be completed, because for any fluid to flow, initial driving force is required and it is fulfilled by the pump by consuming electrical energy and converting it to pressure energy. So, the selection of pump is very important in every field of section, depending on the property of process fluid. The Centrifugal pump is most demanding nowadays because it has simple design, less maintenance, can handle large quantities of fluids, and provides very high flow rates. The Centrifugal pump has mainly two components rotating components and stationary components. Shaft and impeller (open, semi-enclosed, and fully-enclosed) comes under the category of rotating components and casing (Volute, Vortex, and circular) comes under stationary components. Various parameters of process fluid like liquid viscosity, temperature, specific gravity, vapor pressure, concentration, shear sensitive and abrasive or non-abrasive, MOC, pump environment, pressure, flow rate, etc. are calculated to gain the desired efficiency and prevent a problem like cavitation if not properly handled. In this paper, a single-stage centrifugal pump is reviewed and studied how to increase performance and efficiency of centrifugal pump.
\end{abstract} Keywords : Centrifugal pump, Impeller, Single stage centrifugal pump, Shaft.

\section{INTRODUCTION}

A pump is an equipment that is built to move or transfer fluid from one location to another or to lift water from a lower level to a higher level. For any pump to perform its action, it's very essential to provide Electrical energy which is further converted in to pressure energy. As per the requirement of the 
process and application correct selection of pump is very important to get the maximum efficiency. Many small equipment such as electromotor, shaft, stuffing box, gland packing, vane, impeller, casing is clubbed together to form a basic centrifugal pump.

The electromotor is connected with the help of shaft passes through the stuffing box and mounted on the bearings and then connects to the impeller which is covered or present inside the stationary casing. When electromotor is turned on, the mechanical energy is given to the shaft that rotates the impeller having blades or vanes. As a result, on the suction side pressure decreases, which helps the fluid to be pulled towards the centre (eye) of the impeller. when torque is provided to any mass of fluid, the liquid is thrown outwards, starts to move in a curved path with the help of centrifugal force i.e., mechanical energy is converted to kinetic energy by the impeller. Now, kinetic energy acquired by the liquid is converted into pressure energy when it hits the covering casing. The pressure is developed inside the pump which helps to lift the fluid by that pressure called as pressure energy (Hydraulic energy). They are widely used in various industry such as oil and gas industry for pumping crude oil, slurry, mud; used by refineries, power generation plants etc.

\section{PARAMETERS AFFECTING EFFICIENCY}

\section{BLADE ANGLE.}

Sayed Ahmed Imran Bellary, Abdus Samad,et.al studied the blade exit angle has greater effect on the head, shaft power and hydraulic efficiency while the inlet blade angle has relatively less effect on the parameters. As exit blade angle increases the hydraulic efficiency also increases till the experimented value. The efficiency reduces for higher exit blade angles because of different losses. Greater the viscosity lowers the head generation. Increase in fluid density results in increased power consumption at various blade exit angles. With increase in roughness the efficiency value lowers. if both exit blade angle and surface roughness increases simultaneously then it results in increase in head with but no considerable increase in efficiency.[1]

Ajinkya Sonune, Akshay Dudhe and Mahesh R. Chopade,et.al studied increasing blade angle is the fundamental research sector to increase efficiency of centrifugal pumps. Experiment results and evaluation makes it clear that both head and efficiency of centrifugal pumps increases with increasing exit blade angle, the blade angle varies around $35^{\circ}$. Tolerance Value is essential because if angle of the blade is bigger than the estimated, vacuum or void is created in the impeller thereby increasing the spacing in impeller which results in the drop of pressure velocity and mass flow rates. Bigger blade angle constitutes for larger requirement of input power consumption. Increasing blade angle has huge impact on head and the efficiency. If blade angle is smaller than the experimented value it causes clogging of water which deteriorates the performance of centrifugal pumps. But if blade angle is appropriate, the increase in blade angle surely increases the efficiency and all the parameters related to it. It is also seen that variation of one or two percent in blade angle has affected the hydraulic efficiency this point has to be noted because when considering the overall energy consumption of centrifugal pump around the globe this factor cannot be neglected.[2]

M.G.Patel1 , A.V.Doshi,et.al studied the impeller is a crucial part and its geometry plays a major role in the efficiency of centrifugal pump. Changes in impeller design and geometry will impact inlet or exit velocity triangles, which may result in significant performance change. The blade exit angle have greater role in the performance of the centrifugal pump. Here different blade angles are studied to understand its effect on the efficacy and performance of the centrifugal pump. Study from mathematical modelling is selected 
because it is economically effective and easier to solve and understand effect of blade angles on centrifugal pump's performance. It is seen that more the value of exit blade angle more the efficiency and head. The denouement of the analysis was that the blade exit angle has significant and equal effect on the head and the efficiency. With the increase in blade exit angle the performance of the centrifugal pump is increases. There may be some inaccuracy due to the complication of the geometrical dimensions. This could be removed by investigating with numerical analysis by CFD code.[3]

F A. Varley, et.al studied there is no simple relationship between the impeller geometry and the pump performance, the number of vanes and their exit angle are the important factors in understanding the head developed by an impeller of given size. A large number of vanes and a high exit angle will give the maximum output but, beyond certain limits, this will not meet with the requirements of maximum efficiency and a stable head characteristic. Roughness of the impeller surfaces decreases the pump efficiency but increases its output because of the enhanced pumping action of the shrouds.[4]

\section{IMPELLER TRIMMING}

Xiao Qu1 and Li Wang,et.al;studied Impeller Trimming involves reducing the diameter of impeller. Trimming should be $75 \%$ of pumps maximum impeller diameter. If diameter is decreased further than this specification, efficiency degrades which results due to increase in gap between impeller and stator. The main advantage of impeller trimming is, it decreases head, flowrate and power. Impeller trimming therefore is cost effective and is an easy way to increase centrifugal pump efficiency. The greater the impeller reduction and the higher the specific speed of the impeller, the more the pump efficiency will decrease with impeller trimming. Many researchers, by evaluating and experimenting have found out different methods of impeller trimming.

The traditional impeller straight trimming method operation is easy. Straight Trimming reduces pressure difference in the impeller and improves the pressure gradient which decreases the impact losses. But this method reduces the efficiency when there is high flow condition. The leakage loss from impeller increases. It has direct effect on efficiency and heads leading to quick drop in the values.

The miscut blade outlet edge will affect the axial force. It is found out that the miscut angle when is $10^{\circ}$ the efficiency is maximum. The efficiency is higher in positive miscut than in reverse miscut. The pressure difference between the pressure surface and the suction surface is lower when the miscut angle is $10^{\circ}$, and the flow performance is better.

The impeller triangle trimming method avoids the elevation of the performance curve. the impeller trimming area is smaller and leakage loss is reduced, pump's gross efficiency is unaffected. When the angle of trimming decreases there is significant leakage loss. The pressure difference in the impeller outlet becomes more and more uneven thereby increases the impact loss hence heads and efficiency degrade.

Impeller parabolic trimming is cutting a parabolic gap at the outlet edge of the blade. There is no reverse pressure here, so pressure distribution is improved. Hence there is no uneven distribution of pressure, which reduces the impact loss. It is observed that the efficiency and heads are higher than compared to rest methods. shaft power is reduced as compared to other methods.[5]

Mario Šavar a, *, Hrvoje Kozmar a, Igor S b utlović I. Lučića Zagreb, Croatia , et.al studied the pump impeller when trimmed, the geometric and kinematic similarity was not attained. The ratios of 
some dimension's changes and hence it's difficult to attain geometry similarity. As the blade angle varies with radius kinematic similarity is unattainable. Hence some authors suggest that trimming should be limited to about $75 \%$ of a pump's maximum impeller diameter. An excessive trimming can result in an inappropriate measurement of impeller and casing. As the impeller diameter decreases, the clearance increases, causing head loss, and decreases pump efficiency. In the experiment the impeller was trimmed seven times and was accomplished on a low specific speed centrifugal pump. As the trimming increases, as impeller diameter gets smaller efficiency lowers. This could be because of growing the gap between the impeller and stator. [6]

\section{IMPELLER TYPES}

A. Farid Ayad, H.M. Abdalla, A. Abou ElAzm,et.al,studied Centrifugal pump is divided into closed, semi open and open impeller. Closed impeller is that the one with front cowl and without front shroud are known as Semi-Open Impeller, and with giant cut-outs within the rear cover is called as Open Impeller. As a pump rotates quicker, stress because of force within the impeller will increase. Owing to the significant weight of shroud, it will increase the stress due to centrifugal force on impeller and limits the speed at that a pump can operate. Therefore, there's an advantage for semi open impeller owing to absence of shroud and produce more head. Semi-open impeller if gets clogged with solids it is easier to clean also the main advantage is its efficiency and has less probability to clog with solids. The main causes of the performance reduction are the falling-off in the blade loading which leading to decreasing the pressure rise within the impeller. By increasing the side clearance dimension the secondary flow causes a vortex that impedes the core flow and reduces the pressure rise at the semi-open impeller. Because of the decay within the blade loading the force at the blades decreases causes a drop in the impeller input power. Because of the change in the velocity distribution at the impeller outlet the slip factor decreases with increasing the side clearance dimension.[7]

Shyam N. Shukla snshukla, Jagadish Kshirsaga,et.al studied a semi-open impeller has a solids passing capability similar to that found in an open vane. With solely one shroud a semi-open impeller is simple to manufacture and utterly accessible for applying surface hardening treatments. For moderately abrasive slurries a semi-open impeller may be a good selection. Semi-Open impellers are ordinarily used for handling fluids with abrasive particles. These impellers have back shroud and the blades don't have support from front shroud. The designer proposes standard clearance to permit free rotation of impellers in stationary casing. Design clearances are troublesome to take care of throughout producing because it entails for special manufacturing process. It's well established in experiments that each head and potency decrease with increase in tip clearance and are quite sensitive to rather small change in clearance. [8]

\section{PARALLEL AND SERIES ARRANGEMENT OF PUMPS}

Mohammad Emal Qazizada1 and Elena Pivarčiová1 et.al,studied that series pumping is advantageous if used small sized pumps this may reduce installation costs as well as operating costs. Series pumping using two or more smaller pumps provide a high degree of standby capacity. Centrifugal pumps in series can overcome larger head loss than one pump can handle alone. For two identical pumps in series, the head will be twice the head of a single pump at the same flow rate. Centrifugal pumps in parallel arrangement provide a very high percentage of full flow at low cost. When centrifugal pumps are in parallel it provides higher flow rates. When two or more pumps are arranged in parallel, their resulting performance curves are obtained by adding their flow rates at the same head. So basically, higher flow rates are achieved with parallel pumps connection, and the 
series pump connection are used to overcome larger volume. From experimental analysis when connected in series, increases head capacity or when connected pumps in parallel flow rate capacity is increased.[9] In parallel arrangement if the primary pump stops operating the other pump acts as a standby pump that continue the pumping function and supply a high degree of the planning flow demand. However, the speed from the one pump will increase above the quantity that the only pump was delivering when both pumps were running and therefore the head produced by the pump will decrease. Once connected in parallel it ought to be noted that motor is massive for horsepower needed if this is often not done the motor may pack up on overload or fail when the system goes to single pump operation. With dissimilar pumps in parallel proper control of switch-over points is critical. Unless the pumping system is carefully designed and controlled, the smaller head pump could also be closed by a better head pump. Staging the pumps to match the load requirements would produce significant energy savings also it might be further enhanced by also operating the pumps at variable speed. Series pumping can reduce costs by using a combination of smaller pumps instead of one larger pump to accomplish a certain pumping task. Smaller pumps are used because larger pump has high value of NPSH and causes cavitation. Many series pump installations are made with identical pumps, although it's sometimes advantageous to use dis-similar pumps.

It can be seen that putting pumps in series tends to steepen the overall pump curve.

When pumping conditions require very high head, placing pumps in series is advantageous. [10]

\section{ENERGY LOSS}

Hucan HOU a, Yongxue ZHANGb* , and Zhenlin LI ,et.al drew some results from their study. Local entropy production method was used and this was taken from second law of thermodynamics. The energy loss is mainly formed due to entropy production which is due to turbulent dissipation and wall viscous friction. The direct dissipation entropy production is very less related to energy loss. The energy is produced by turbulent dissipation and wall friction is $47.91 \%$ and 48.615respectively. This entropy production is at the rate of $200 \mathrm{~m} 3 / \mathrm{hr}$. There is a lack between impeller and volute in two calculation ways whereas this lack is not present in the inlet and outlet duct results. The main reason for big deviation for pump water volute. The rate volumetric entropy production rate. The entropy production rate is also very common in the leadingedge regions. Whereas the leading edge near suction side, the trailing edge and volute tongue are main regions.[11]

Hongyu Guan1, Wei Jiang1 , Jianguo Yang1, Yuchuan Wang1, Xinghai Zhao2 and Junxue Wang,et.al studied double suction centrifugal pump in energy loss. In this paper, energy loss is studied with the help of principle of entropy generation under different flow rates. From this, reason and place of energy loss is found out. Generation of entropy of wall function optimization is in good terms with hydraulic loss. This has been studied by theoretical and experimental violations. The main flow region is the reason for the changes in entropy production at various flow rates.0.7Qd and $1 \mathrm{Qd}$ is the range of mainstream entropy production. Volute is the main reason for the production of entropy in the mainstream Improvement in flow field of suction chamber and impeller is done by increase in rate of flow. This helps in reduction in energy loss. The proportion of energy production of suction point is less than $0.5 \%$. Vortex, a flow separation generated on suction side and the impact at leading edge of blades are the reason of hydraulic loss of impeller with the unstable flow in suction chamber. Because of structural characteristics of double volute, there is a variation in flow fields on other side of baffles. This is the reason that flow is not same. And due to this the 
entropy production lies only between $0.7 \mathrm{Qd}$ and $0.9 \mathrm{Qd}$. Due to small flow rate, there is generation of wake flow due to impeller. This causes production of entropy. This is concentrated near the volute. The main and important reason of loss of energy is large angle of attack.[12]

Jingze Li, Dongrong Meng, and Xun Qiao et.al, uses the energy production study. This is used to study energy loss in pumps as turbines. In PATs, highest energy loss is due to guide vanes and least energy loss takes place in volute. The loss in volute is due to its structure which is not symmetrical and thus causes loss in hydraulics. At the tongue of volute, the main losses of the volute are considered. Mainly types of this loss are friction loss and impact loss. There are mainly three reasons for loss in guide vanes. These are separation of flow in flow channel, impact of leading edge of blade and blade wake. In the impeller, two main reasons for the loss where separation of flow and wake flow. The area of impeller and guide vanes are very much affected by the rotor shaft interaction. The main effect of impeller is due to effect of interaction of rotor interaction of impeller and guide vane and guide is affected by interaction of impeller and volute. Vibration of turbine is also called due to this rotor interaction. The main aim of this research is to study and improve stability of pump.[13]

\section{TYPES OF CASING}

M. C. Roco , P. Nair, G. R. Addie, et.al ,proposed a new quasi three dimensional approach. In accordance to application to centrifugal pump casing of slurry flow. Periodic flow has been caused by finite number of infinite blades over the typical impeller of this periodic flow, governing equation were averaged and also over local averaging volumes. All this was done to reduce computational work. The given approach was useful for large secondary currents and lateral inflow and also on pump casings. On two consecutive computational stream tubes which are connecting two radial parts, consideration of mass and momentum transfer is done. In a radial cross section for the upstream effects, these mass and momentum transfer were adopted. Arc represents the recirculation flow rate and was calculated in pump casing of this centrifugal pump. This value found changes with some properties such as casing shape in the perpendicular plane, width of casing, ratio of $\mathrm{Qn} / \mathrm{Q}$ and inflow of impeller. More head losses were found due to internal recirculation and also the wear rates. These conditions were specially seen where $\mathrm{Q}$ was different from $\mathrm{Qn}$. The head loss of the casings was obtained due to factors like casing geometry function, flow rate, speed of pump rotation, characteristics of solid and many more. By considering the loss of energy also wear due to erosion, this study is very useful for optimization of geometry of casing and also for parametric studies [14]

Ravindra Kumar et.al, studied the radial thrust in a single volute pump. Some of the operational measures are carried in order to improve life of a bearing in a pump of single volute He noticed that there is an increase in radial thrust when the value of $\mathrm{Q} / \mathrm{Qd}$ changes. It means that operation of the pump has to be done very near to BEP. Addition of a bypass line is done in order to avoid the effect of load of radial on shaft when it is very away from the highest efficiency point of pump. This addition is done to the suction pipe from the discharge header. But this process leads to the reduction in overall pump efficiency. Some of the measures were also taken for shaft design. This gives long life of shaft. The shaft should be used which has very high endurance limits, shafts which have threads in middle portion should be avoided. In order to avoid stress, proper fillet should be there in key. Some measures of casing design were also studied. The effect on radial clearance in between the impeller and casing. The volute angle increases with increase in specific speed which increases due to radial thrust factor. The casing is divided in 2 parts at 180 degrees apart. 
HEAD

Head of pump can be described on the performance of Pump with the help of Newtonian fluid.

The pump has Following types:

Total Static head - Total head when the pump is not running.

Total Dynamic head - Total head when pump is running

Total Static Suction head - Head is on the Suction side, with pump Static head Pump off

If pump impellers Static suction head lower than head on Suction Side. But if pump head impeller Static Suction head in higher than pump impeller Static discharge then head on discharge.

Head on discharge side of pump is either measured in feet on meters \& Converted to Unit pressure. for e.g., Psi, Pa or bar. If the discharge of pump is pumped to a particular height in air, then the such type of head is called shut off head. Head is mainly determined by outside the diameter of Pump \& Speed of shaft. As Capacity of pump changes, head will also change. The kinetic energy of fluid passing through an impeller is determined by resistance in the flow.

Firstly, Pump casing generates resistance when liquid or fluid Enters pump \& decreases its speed. When the speed of Fluid decreases, kinetic energy gets converted to Pressure Energy and amount of resistance is measured in pressure gauge which is attached at the discharge pipe. Pressure is not generated by Pump Only resistance is generated where; Pressure gauge is instrument which measure resistance of Flow. In the term of liquid head is used for measuring kinetic energy which is generated by Pump. The reason for using head to measure Pump's energy instead of pressure is because Pressure from pump changes to specific gravity of fluid changes but in head it does not changes. If shaft is turning at same rpm. then pump will pump all liquid to same height. But there is deference in amount of power of fluid takes to give shaft Same rpm. If specific gravity is high, then more power is required. Therefore, centrifugal pump is called as constant head machines But, it is not constant pressure machine. Thus, Pressure is Function of head \& density. The head is constant even if pressure changes or density changes. Head can be described in simple term of vertical discharge, pressure head which is vertical lift in height and measured in feet or $\mathrm{m}$ of water. It is also determined in a pressure at which water move. At this point pump reaches its shut off head pressure. [16] The curve can be determined on $\mathrm{x}$ and co-ordinates which depends on Specific speed \& Single or multistage. In this method normalized Fluid \& gas rates are used. In addition to that, Complementary chart gives head coefficient ratio curve versus inlet gas void fractions.

\section{SPECIFIC SPEED}

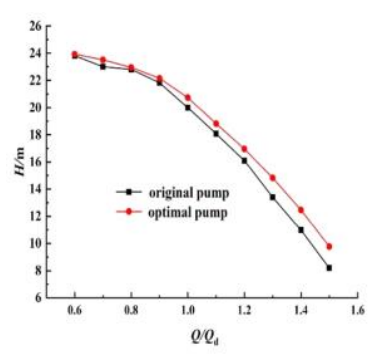

(a)

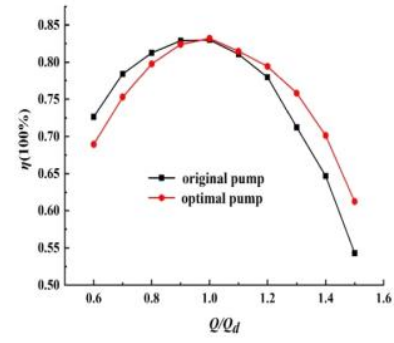

(b)
In above diagram (a) head of optimal pump \& higher than the original pump in all working conditions. At low flow rate $\left(0.6 \mathrm{Q}_{\mathrm{d}}-1.0 \mathrm{Q}_{\mathrm{d}}\right)$, the optimal pump has small head increment. but it becomes large with the increase of flow rate. At design Flow Rate head of original is $19.99 \mathrm{~m}$ \& optimal pump is $20.74 \mathrm{~m}$. And after optimization head increased by $3.75 \%$ under 1.5 times design flow rate the optimal \& original pump head is $9.17 \mathrm{~m} \& 8.19 \mathrm{~m} \&$ head increment reaches to $12 \%$. 
we can observe in diagram (a) the trend of efficiency changes and head change both are different. In the low Flow region $\left(0.6 \mathrm{Q}_{\mathrm{d}}-1.0 \mathrm{Q}_{\mathrm{d}}\right)$ optimal Pump is lower than original pump. At $0.6 \mathrm{Q}_{\mathrm{d}}$, the efficiency of original pump is $3.7 \%$ higher than $\left(0.6 \mathrm{Q}_{d}-1.0 \mathrm{Q}_{d}\right)$ the optimal pump. However, in high flow rate region the optimal curve efficiency is lower than efficiency of the optimal Pump \& value decreases by $6.9 \%$, at 1.5 Qd.

As we can see in diagram with the change of head is very small is NPSHa (available net positive Suction head) is decreases. Head Starts decline faster when NPSHa decreases at a certain value. NPSHr (required net Positive Suction head) Corresponds when head drops by $3 \%$. If NPSHr is greater then pressure drop will be greater and anti-cavitation Performance of pump is worse. The NPSHr Optimal pump is $5.38 \mathrm{~m}$, which is smaller than that of 5.92 for original Pump, which achieves improvement on anti-cavitation performance. [17]

\section{CAVITATION}

Cavitation can have a serious negative impact on pump operation and lifespan. It can affect many aspects of a pump, but it is often the pump impeller that is most severely impacted. A relatively new impeller that has suffered from cavitation typically looks like it has been in use for many years; the impeller material may be eroded and it can be damaged beyond repair. Cavitation occurs when the liquid in a pump turns to a vapour at low pressure. It occurs because there is not enough pressure at the suction end of the pump, or insufficient Net Positive Suction Head available (NPSHa). When cavitation takes place, air bubbles are created at low pressure. As the liquid passes from the suction side of the impeller to the delivery side, the bubbles implode. This creates a shockwave that hits the impeller and creates pump vibration and mechanical damage, possibly leading to complete failure of the pump at some stage. The impact of cavitation on a pump Cavitation causes pump performance deterioration, mechanical damage, noise and vibration which can ultimately lead to pump failure. Vibration is a common symptom of cavitation, and many times the first sign of an issue. Vibration causes problems for many pump components, including the shaft, bearings and seals. What causes cavitation? Cavitation occurs in a pump when the temperature and pressure of the liquid at the suction of the impeller equals the vapour pressure. It can happen at low pressures and normal operating temperatures. Bubbles form during cavitation. As the pressure in the pump increases, those bubbles collapse in the form of an implosion - equally as violent as an explosion. The implosion causes shockwaves to travel through the liquid and hit the impeller causing mechanical damage.

NPSH is defined as the difference between the pressure available at the pump inlet and the vapour pressure of the liquid. Vapour pressure is different for different liquids and varies with pressure and temperature. The pressure available at the pump inlet is what remains after friction loss, velocity head loss and inlet and outlet losses have been taken into account within the suction pipework of the pumping system. Because of this, during the design phase, it is necessary to calculate these losses and process unit losses in the suction pipework and then deduct those losses from the suction head available to the pump. By doing this, at the point where the pump is installed, one is left with net pressure remaining and available for the pump. [20]

In centrifugal pumps, cavitation performance mostly depends on the impeller geometrical design such that, any geometry modification can result in a different performance. Therefore, the design process requires a more careful control, such that, through experimental and numerical methods, the centrifugal pump's performance is often well predicted where cavitation can be decreased to acceptable levels if not completely eliminated. Xuanwu L.46 [2008], experimentally and numerical simulation, studied the effect of the blade profile on pump cavitation 
performance during a miniature pump. Two semiopen impellers, the primary with leaned blades the second with two-dimensional blades, were studied; where $\mathrm{k}-\varepsilon$ turbulence model and VOF cavitation model were used for the simulation process. The leaned blades were found preferential to both the hydraulic and cavitation performance; however, the increase in axial tip clearance was found to make the pump cavitation performance even worse. Xianwu L.47 [2008] again carried out an experimental and numerical research on the influence of impeller inlet geometry on pump cavitation performance. The pump inlet geometry proved to be influential when it comes to centrifugal pump performance, where greater blade leading edge and blade inlet angle positively affected the pump hydraulic performance and cavitation performance respectively. [21]

\section{CONCLUSION}

Centrifugal Pump plays a crucial role in industries. In this review paper, some of the parameters were discussed that affect the efficiency of centrifugal pump. The centrifugal pump efficiency depends on design parameters such as the Blade number, blade geometry and the casing shape and size; and operational parameters like the impeller rotational speed and the pump flow rate, Different researchers, Qing Zhang et Al 10 [2014] Rouhollah Torabi and Seyyed Ahmad Nourbakhsh et.al, Xian Luo et Al 11 [2008] and many others, carried out studies of parameters affecting pump performance, where different design parameters such as the impeller inlet diameter, blade inlet angle, and inlet blade thickness, showed a great importance in terms of pump performance improvement. In denouement, any changes in geometry of centrifugal pump can result in a totally different performance. Pump efficiency is also affected by pump rotational speed, especially high speeds and specific heads.

\section{REFERENCES}

[1]. Sayed Ahmed, Imran Bellary , Abdus Samad, Published:9 June 2015 Pumping crude oil by centrifugal impeller having different blade angles and surface roughness J Petrol Explor Prod Technol (2016) 6:117, 10.1007/s13202-015-0173-y

[2]. Ajinkya Sonune, Akshay Dudhe and Mahesh R. Chopade Accepted 12 March 2017, Available online 16 March 2017, Special Issue-7 (March 2017) International Journal of Current Engineering and Technology E-ISSN 2277 - 4106, P-ISSN 2347 - 5161

[3]. M.G.Patel1 , A.V.Doshi2 1MED, CKPCET, Surat, Gujarat, India 2MED, SVNIT, Surat, Gujarat, India Effect of Impeller Blade Exit Angle on the Performance of Centrifugal Pump International Journal of Emerging Technology and Advanced Engineering

[4]. By F. A. Varley, M.Sc. (Eng.), Ph.D. (Associate Member)* EFFECTS OF IMPELLER DESIGN AND SURFACE ROUGHNESS ON THE PERFORMANCE OF CENTRIFUGAL PUMPS

[5]. Mario Šavar a, *, Hrvoje Kozmar a , Igor Sutlović b Improving centrifugal pump efficiency by impeller trimming Article history: Accepted 27 November 2008 Available online 6 October 2009 (c) 2009 Elsevier B.V. All rights reserved.

[6]. Xiao Qu1 and Li Wang2 Effects of Impeller Trimming Methods on Performances of Centrifugal Pump 2016 American Society of Civil Engineers 10.1061/(ASCE)EY.1943-7897.0000343

[7]. A. Farid Ayad, H.M. Abdalla, A. Abou El-Azm Effect of semi-open impeller side clearance on the centrifugal pump performance using CFD 28 September 2015 AESCTE 3439

[8]. Shyam N. Shukla snshukla Jagadish Kshirsagar NUMERICAL SIMULATION OF TIP CLEARANCE FOW IN SEMI-OPEN IMPELLER PUMP July 30August 2, 2007 5th Joint ASME/JSME Fluids Engineering Conference FEDSM2007-37355

[9]. Mohammad Emal Qazizada1 and Elena Pivarčiová1 Reliability of parallel and serial centrifugal pumps for dewatering in mining process Volume 23 (2018) number 2 Acta Montanistica Slovaca, 141-152

[10]. Bell \& Gossett Parallel and Series Pump Application TECHNICAL BROCHURE TEH-1109A 
[11]. Hucan HOU , Yongxue ZHANG , and Zhenlin LI Year 2017 A NUMERICAL RESEARCH ON ENERGY LOSS EVALUATION IN A CENTRIFUGAL PUMP SYSTEM BASED ON LOCAL ENTROPY PRODUCTION METHOD Hou, H., et al.: A Numerical Research on Energy Loss Evaluation in a Centrifugal Pump ... THERMAL SCIENCE: Year 2017, Vol. 21, No. 3, pp. 1287-1299 https://doi.org/10.2298/TSCI150702143H

[12]. hongyu Guan1, Wei Jiang1, Jianguo Yang1 , Yuchuan Wang1, Xinghai Zhao2 and Junxue Wang Energy loss analysis of the double-suction centrifugal pump under different flow rates based on entropy production theory Proc IMechE Part C: J Mechanical Engineering Science IMechE 2020 DOI: $10.1177 / 0954406220919795$

[13]. Jingze Li , Dongrong Meng, and Xun Qiao Numerical Investigation of Flow Field and Energy Loss in a Centrifugal Pump as Turbin Hindawi Shock and Vibration Volume 2020, Article ID 8884385, 12 pages https://doi.org/10.1155/2020/8884385

[14]. M. C. Roco Professor. Mem.ASME P. Nair Research Assistant. Department of Mechanical Engineering, University of Kentucky, Lexington, KY 40506-0046 G. R. Addie Professional Engineer, GIW Industries, Inc. Casing Headloss in Centrifugal Slurry Pumps DECEMBER 1986, Journal of Fluids Engineeringhttp://www.asme.org/about-asme/termsof-use

[15]. Ravindra kuamr,mechanical maintenance Panipat refinery,indian oil coorporation limited panipat,haryana,india-132140 Radial Thurst in a Single Volute Centrifugal Pump International Journal of engineering research and technology (IJERT) ISSN:2278-0181 vol.7 issue 08, August 2018 "http://www.ijert.org/"http://www.ijert.org

[16]. Xylem Applied Water Systems August 2015

[17]. A Review of Design Considerations of Centrifugal Pump Capability for Handling Inlet Gas-Liquid TwoPhase Flows Qifeng Jiang 1, Yaguang Heng, Xiaobing Liu, Weibin Zhang, Gérard Bois 2, and Qiaorui Si ${ }^{3}$ Received: 19 February 2019, Accepted: 15 March 2019; Published: 20 March 2019 Energies2019,12,1078

[18]. The effect of viscosity on performance of a low Specific speed centrifugal pump. Author - Roubollah
Tonabi \& Seyyed Ahmad Nourbaksh Jennial International journal of Rotating machinery Received 26 March 2016, Revised 21 May 2006 Accepted 29 May 2006

[19]. Performance Optimization of High Specific Speed Centrifugal Pump Based on Orthogonal Experiment Design Method Author- Zikang L, Hongchang Ding, Xiao Shen and Yongming Jiang -Processes 2019, 7, 728 Received: 16 September 2019; Accepted: 3 October 2019, Published: 11 October 2019

[20]. https://www.engineeringtoolbox.com/centrifugalpumps-d_54.html

[21]. Maxime Binamaa , Alex Muhirwaa,b , Emmanuel Bisengimanac Cavitation Effects in Centrifugal Pumps- A Review , Vol. 6, Issue 5, (Part - 1) May 2016 Binama Maxime.Int. Journal of Engineering Research and Applications pp.52-6

\section{Cite this article as :}

Shivani Kaustubh Chitale, Pranjal Nitin Jadhav, Snehal Suresh Dhoble, Dr. Mr. Satyajeet Deshmukh, "Parameters Affecting Efficiency of Centrifugal Pump - A Review", International Journal of Scientific Research in Science and Technology (IJSRST), Online ISSN : 2395-602X, Print ISSN : 2395-6011, Volume 8 Issue 6, pp. 49-58, November-December 2021. Available at

doi : https://doi.org/10.32628/IJSRST218573

Journal URL : https://ijsrst.com/IJSRST218573 